\title{
Production and analysis of a biosimilar erythropoietin in Egypt
}

This article was published in the following Dove Press journal:

Biosimilars

10 May 2014

Number of times this article has been viewed

\section{Wael M Ebied' \\ Hytham M Ahmed ${ }^{2}$ \\ Fawzy A Elbarbry ${ }^{3}$}

'SEDICO Pharmaceuticals, Merck \& Co External Partner, 6th of October City, Cairo, ${ }^{2}$ Pharmaceutical Analysis Department, Faculty of Pharmacy, Damanhour University, Damanhour, Egypt; ${ }^{3}$ Pharmaceutical Sciences, School of Pharmacy, Pacific University Oregon, Hillsboro, OR, USA

Video abstract

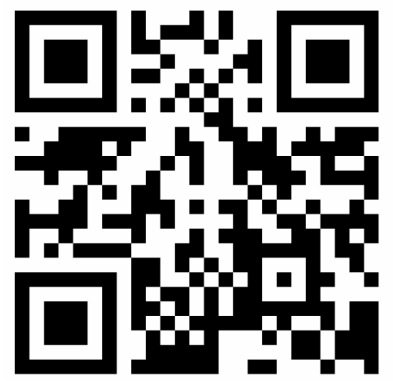

Point your SmartPhone at the code above. If you have a QR code reader the video abstract will appear. Or use: http://dvpr.es/lijBijk
Correspondence: Fawzy A Elbarbry Pacific University Oregon, 222 SE 8th Ave, Hillsboro, OR 97I23, USA

Tel +l 5033527356

Fax +I 5033527270

Email fawzy.elbarbry@pacificu.edu
Abstract: Although management of chronic diseases has been a major challenge for health care systems in developed and developing countries, biopharmaceuticals have been successful in treating many life-threatening conditions. However, the high cost of these agents restricts their availability to countries where patients and/or health care systems are able to afford them. Licensing these biopharmaceuticals as biosimilars after expiration of their patents might increase access to such medicines at an affordable price in developing countries. South Egypt Drug Industries Company (SEDICO) is an Egyptian pharmaceutical company that has had the opportunity to manufacture some of these drugs. SEDICO biotechnology products, such as insulin, erythropoietin, streptokinase, angiokinase, follicle-stimulating hormone, aprotinin, filgrastim, and somatropin, have been available on the Egyptian market for more than 6 years. For this paper, erythropoietin, which has been investigated over a number of years, was chosen as a representative example of SEDICO biotechnology products. Our findings confirm that SEDICO erythropoietin can compete with the originator epoetins on the Egyptian market with high quality and at a lower cost.

Keywords: biosimilars, developing countries, insulin, human growth hormone, erythropoietin, epoetin, Egypt

\section{Introduction}

Biopharmaceuticals have become important therapeutic options for treating a variety of diseases, especially after recombinant technology made it possible to produce therapeutic proteins. ${ }^{1}$ The last few years have seen expiration of the patents covering several recombinant DNA-derived biopharmaceuticals, such as Humulin ${ }^{\circledR}$ (Eli Lilly and Company, Indianapolis, IN, USA), Intron $A^{\circledR}$ (Schering-Plough; Merck \& Co., Inc., Whitehouse Station, NJ, USA), Procrit $^{\circledR} /$ Eprex $^{\circledR}$ (Janssen-Cilag Ltd, High Wycombe, UK), and Neupogen ${ }^{\circledR}$ (Amgen Inc., Thousand Oaks, CA, USA). ${ }^{2}$ Therefore, there is an opportunity for pharmaceutical companies all over the world to develop and market generic versions of these molecules, commonly known as "biosimilars", "biogenerics", or "follow-on biologics". 3-5

Unlike small-molecule pharmaceuticals, biopharmaceuticals are complex proteins that require a complicated manufacturing process with several isolation and purification steps. Manufacturing procedures are generally the exclusive knowledge of the inventor company, so it is a challenge for the manufacturer of a biosimilar to produce a final product similar to the innovator product even though they contain the same active substance. ${ }^{6}$ Final biosimilar products with structures that are different from the innovator products will not only vary in efficacy, but also in their potential to affect the patient's immune response..$^{6-8}$ 
As biosimilars continue to enter the Egyptian pharmaceutical market, they not only offer huge cost savings for patients, physicians, insurance providers, and governments, but also add to the physician's list of treatments available for a variety of diseases. ${ }^{9}{ }^{10}$ Several studies have concluded that biosimilar epoetin- $\alpha$ is the most cost-effective erythropoiesisstimulating agent available for managing chemotherapyinduced anemia using both fixed and weight-based dosing strategies. Using fixed-dosing scenarios, the average cost savings associated with use of biosimilar epoetin- $\alpha 40,000$ IU ranged from $€ 990$ (13.8\%) to $€ 3,042$ (33.0\%), while for biosimilar epoetin- $\alpha 30,000$ IU the average savings ranged from $€ 2,534$ (35.4\%) to $€ 4,587$ (49.7\%). ${ }^{11}$ For weight-based dosing, the cost savings with the use of biosimilar epoetin- $\alpha$ ranged from $€ 757$ (13.8\%) to $€ 3,738$ (44.2\%).

This paper describes first-hand Egyptian experiences with hematopoietic biosimilar recombinant medicines in an attempt to guide launching plans for follow-on biologics in the USA and other parts of the world. A representative example, ie, recombinant human erythropoietin (EPO), was chosen as the Egyptian biosimilar of epoetin. While all epoetin products on the market have an amino acid sequence similar to that of endogenous erythropoietin, they differ in the manufacturing protocols used. Importantly, variations in glycosylation patterns affect the pharmacokinetics of a product, and may impact efficacy, safety, and immunogenicity. ${ }^{12,13}$

The introduction of EPO has minimized the need for blood transfusions in the treatment of anemia associated with chronic kidney disease. ${ }^{14}$ EPO is also used to treat chemotherapy-induced anemia by increasing hemoglobin levels and reducing the need for red blood cell transfusions in cancer patients on chemotherapy. ${ }^{15-17}$

\section{Materials and methods Analysis of EPO}

A concentrated (raw bulk) solution of EPO was provided by two separate suppliers, ie, Supplier A (Zelltek S.A., Santa Fe, Argentina), and Supplier B (Sciprogen Bio-pharmaceutical Co., Ltd, People's Republic of China). In all cases, South Egypt Drug Industries Company (SEDICO) biotechnology and quality control laboratories followed the most recently published European Pharmacopoeia tests. ${ }^{18}$ The European Pharmacopoeia monograph 1316 specifies that identification and assay of erythropoietin concentrated solution requires the use of a reference preparation ${ }^{18}$ preceded by detailed validation of the analytical test methods, including specificity, linearity, accuracy, and precision, which are not included in the present work. Testing for host cell-derived proteins in the concentrated solution was done by the supplier and the limits are approved by the relevant regulatory authority. The concentrated solution was slightly turbid and colorless. A capillary zone electrophoresis assay was used to identify the EPO concentrated solution. The chromatographic profile obtained for the test solution corresponded to that for the reference solution.

\section{Potency and protein content}

An enzyme-linked immunosorbent assay (ELISA) was used to determine the quantities of biological molecules in vitro.

\section{Immunogenic response}

Immunogenicity is the most important safety issue with biosimilars. Although it is necessary to compare manufactured batches of a product with a traditional reference product during preauthorization studies, the sensitivity and specificity of the assays used to test for immunogenic responses may still be inadequate to predict rare cases of immunogenicity. Further, these methods usually lack adequate standardization and validation, making it practically impossible to differentiate antibody titers from different laboratories. ELISAs have been validated for screening new EPO products. ${ }^{19}$ These assays, with high sensitivity and efficiency, automatically recognize all antibody isotypes and correlate well with the radioimmunoprecipitation assay. ${ }^{20}$ However, because of their limitations, these tests should be used in a complementary manner and not as a substitute for clinical trials.

\section{Clinical study}

A multicenter clinical study was performed to compare the side effect profiles of EPO and other erythropoietin products. The study was of 12 weeks' duration and approved by the Ministry of Health executive committee (IRB8000068). Forty patients (20 female and 20 male) of mean age 44.5 (range 17-70) years and with end-stage kidney disease were included. All had either not been on recombinant human EPO previously or had been weaned off it for at least 2 weeks before enrollment. A history of hypertension was reported upon study entry for 12 patients, in whom blood pressure remained stable throughout the study. Inclusion criteria included ability to provide signed informed consent and development of anemia while receiving dialysis for chronic end-stage kidney disease. Anemia was defined as a $\leq 10 \mathrm{~g} / \mathrm{dL}$ decrease in hemoglobin level. Patients on hemodialysis for chronic end-stage kidney disease who did not develop anemia during treatment, those with primary hematological disease, and those with known hypersensitivity to mammalian cell-derived products or known hypersensitivity to albumin were excluded. 


\section{Instrumentation}

The following instruments and techniques are used for the manufacture and analysis of EPO in our laboratories: a P/ ACE ${ }^{\mathrm{TM}}$ MDQ capillary electrophoresis system (Beckman Coulter, Pasadena, CA, USA) and an XR 680 ELISA reader, Mini-Trans Blot ${ }^{\circledR}$ electrophoretic transfer cell, Mini-PROTEAN ${ }^{\circledR}$ tetra cell, 1575 Immunowasher, 583 Gel Dryer, and Bio-Dot ${ }^{\circledR}$ microfiltration system (all from BioRad, Hercules, CA, USA). Breeze (Waters Corporation, Milford, MA, USA), 1200 series (Agilent, Santa Rosa, CA, USA), and LC 2010 C (Shimadzu Corporation, Tokyo, Japan) high-pressure liquid chromatography (HPLC) systems are also used, along with a spectrophotometer (Shimadzu Corporation) and a limulus amebocyte lysate assay for bacterial endotoxins.

\section{Statistical analysis}

All data were reported as the mean \pm standard deviation. Significant differences in variables, such as hemoglobin, red cell count, hematocrit, and protein content between groups were assessed by one-way analysis of variance with Tukey's post hoc test for pairwise multiple comparisons using GraphPad Prism version 4 (Graphpad Software Inc., La Jolla, CA, USA). A $P$-value $<0.05$ was considered to be statistically significant.

\section{Results and discussion Immunogenicity}

High pressure size exclusion chromatography and sodium dodecyl sulfate polyacrylamide gel electrophoresis did not detect any aggregates in the tested EPO products, suggesting a low risk of an aggregate-induced immune response. The EPO products differed in glycosylation, potency, and content, even within a single batch. Marked batch-to-batch differences in glycosylation have been reported elsewhere. ${ }^{21}$

\section{Specific activity of EPO concentrated solution}

This test was performed by the supplier of the raw material, and the data are presented with batch numbers and EPO in IU/mg in Figure 1. Control charts were constructed on the assumption that the data were normally distributed with a mean of $115,075 \mathrm{IU} /$ $\mathrm{mg}$ and a standard deviation of 10,174.36 IU/mg. In the middle of the chart, some points are seen on the margin of the lower specification limit but are followed by a clear improvement due to upgrading of the raw materials provided by supplier B.

\section{Sialic acid testing of concentrated EPO solution}

The overall therapeutic efficacy of biopharmaceutical proteins such as EPO has been found to improve significantly with hypersialylation, ${ }^{22}$ and may be attributable to sialic acids on prokaryotic and eukaryotic cells. In mammalian cells, sialic acids occupy the terminal positions on oligosaccharide chains and are constituents of several biologically important glycoproteins. ${ }^{23}$ Therefore, binding to sialic acids might represent an initial event in the binding of macromolecules for initiation of biological activity. Sialylation is an effective and less challenging alternative to polyethylene glycol (PEG)-ylation for increasing the half-life of therapeutic proteins such as erythropoietin. ${ }^{22}$ As shown in Figure 2, the concentration of sialic acid was moderately acceptable in the first batches of raw material from supplier A, but there was a noticeable decrease in the concentration of sialic acid in the raw material from supplier B. Therefore, new EPO with a higher concentration of sialic acid was ordered from supplier B, with satisfactory results.

\section{Protein content in EPO concentrated solution}

Protein content results were collected from the laboratories at SEDICO and those of the suppliers of the raw material,

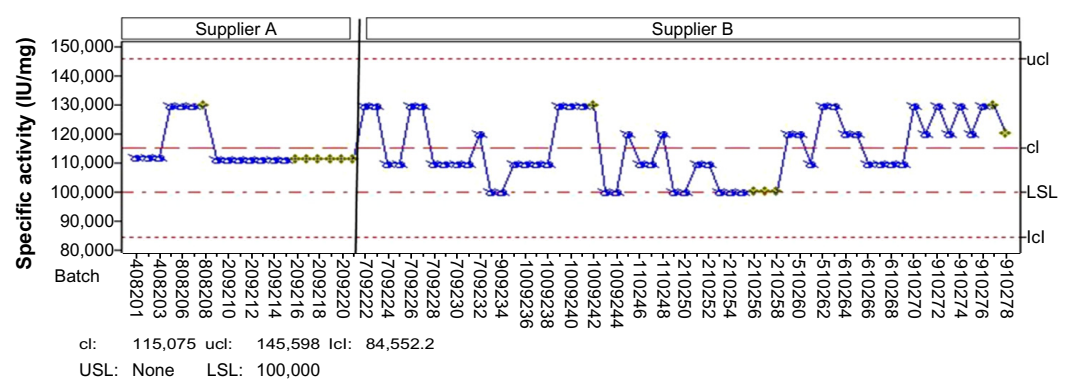

Figure I Specific activity results of concentrated EPO solution (NLT 100,000 IU/mg).

Notes: Supplier A is Zelltek S.A. (Santa Fe, Argentina). Supplier B is Sciprogen Bio-pharmaceutical Co., Ltd (People's Republic of China). Blue points means in control normal variability. Green points means trending within control.

Abbreviations: EPO, recombinant human erythropoietin; NLT, not less than; USL, upper specification limit; LSL, lower specification limit; ucl, upper control limit; Icl, lower control limit; cl, center line (mean). 


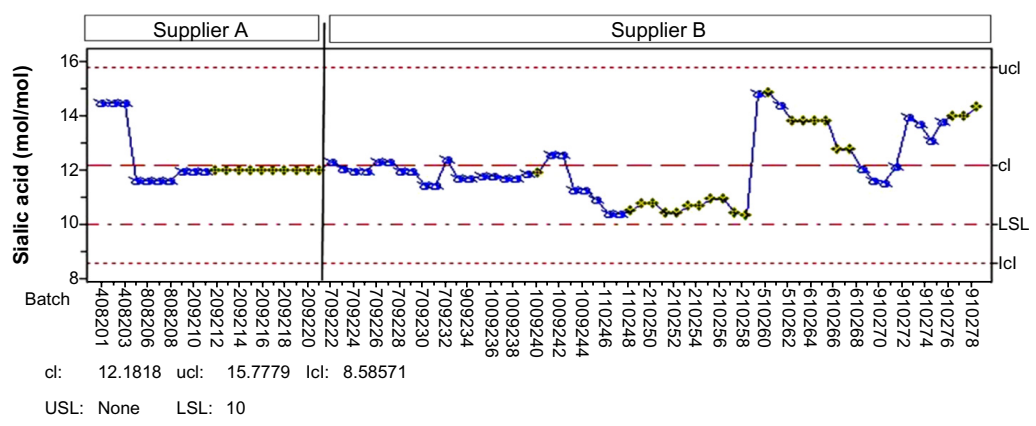

Figure 2 Sialic acid of concentrated EPO solution (NLT $10 \mathrm{~mol} / \mathrm{mol})$

Notes: Supplier A is Zelltek S.A. (Santa Fe, Argentina). Supplier B is Sciprogen Bio-pharmaceutical Co., Ltd (People's Republic of China). Blue points means in control normal variability. Green points means trending within control.

Abbreviations: EPO, recombinant human erythropoietin; NLT, not less than; USL, upper specification limit; LSL, lower specification limit; ucl, upper control limit; Icl, lower control limit; cl, center line (mean).

as shown in Figure 3. No significant difference in assay results for protein content was observed between the suppliers and SEDICO.

\section{Protein percentage}

The percentage of protein in EPO concentrated solution was determined at the SEDICO laboratory. As shown in Figure 4, the normal distribution of points was disrupted by the rescue phase. Consequently, raw materials of higher quality were ordered from supplier B.

\section{Dimers and related substances of higher molecular mass}

Testing for dimers and related substances of higher molecular mass was done using the raw EPO solution. As shown in Figure 5, a constant trend line was achieved after some initial disruption.

\section{Host cell-derived proteins}

The results shown in Figure 6 indicate an improvement in the quality of raw materials after the first three batches and a normal distribution is then seen along the chart.

\section{Bacterial endotoxins}

As shown in Figure 7, the EPO batches were tested for bacterial endotoxin content and the results showed less than $20 \mathrm{IU}$ per $100,000 \mathrm{IU}$ of erythropoietin, which is acceptable. To ensure low pyrogenicity, some batches were analyzed and the result was less than $0.5 \mathrm{IU}$ per 100,000 IU, which is acceptable.

\section{Capillary zone electrophoresis isoforms}

Figures 8-10 show that the percentage content of isoform 3 was higher in the raw material provided by supplier B whereas the percentage content of isoform 5 was higher in that provided by supplier A. There were no significant differences between supplier A and supplier B with regard to isoforms 1, 2, 4, 6, 7, and 8 .

\section{Biological activity}

The biological properties of the raw materials used for EPO and the finished product could be measured in vitro or in vivo. However, in vitro assays are more informative options when testing for activity such as binding of an antibody to a specific target. Biological assay of 24 batches of finished vial product (Figure 11) showed the potency to be within $80 \%-125 \%$ of the range stated on the labeling to be acceptable ( $95 \%$ confidence

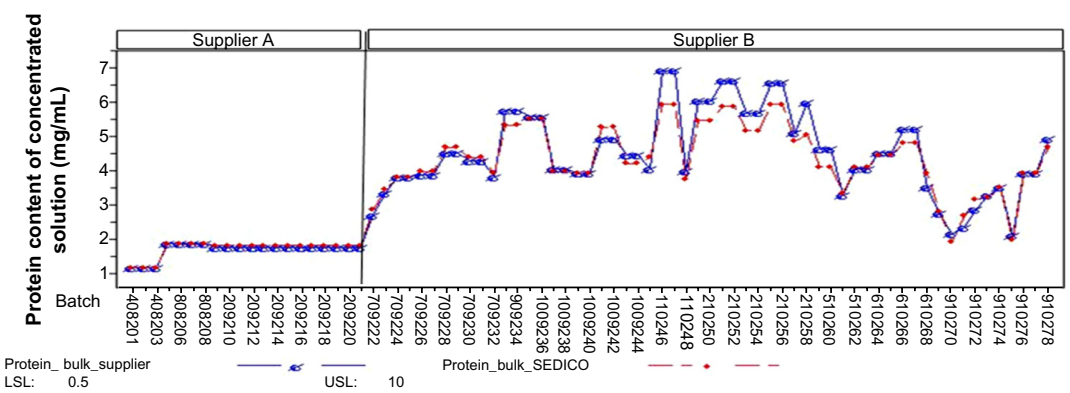

Figure 3 Protein content results of concentrated solution $(0.5-10 \mathrm{mg} / \mathrm{mL})$.

Notes: Supplier A is Zelltek S.A. (Santa Fe, Argentina). Supplier B is Sciprogen Bio-pharmaceutical Co., Ltd (People's Republic of China).

Abbreviations: LSL, lower specification limit; USL, upper specification limit; SEDICO, South Egypt Drug Industries Company. 


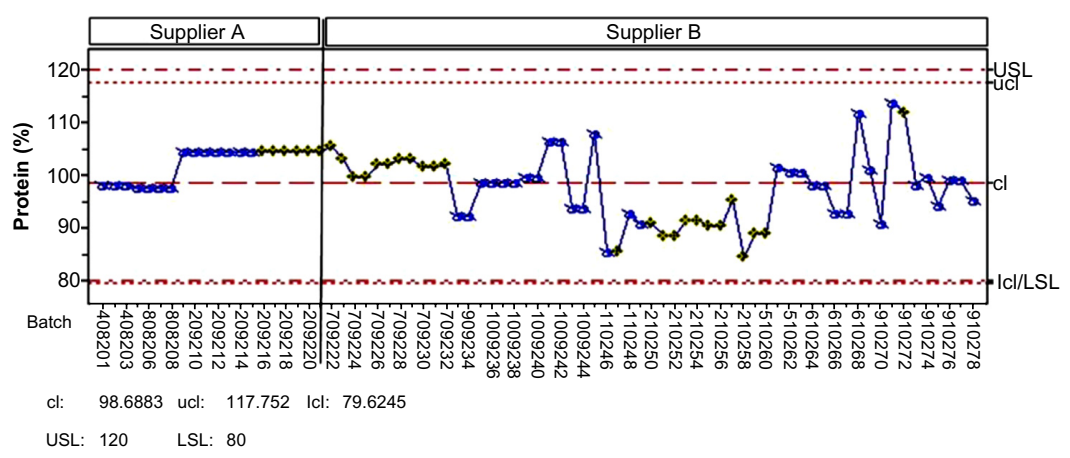

Figure 4 Protein percentage of concentrated EPO solution ( $80 \%-120 \%$ of the stated concentration).

Notes: Supplier A is Zelltek S.A. (Santa Fe, Argentina). Supplier B is Sciprogen Bio-pharmaceutical Co., Ltd (People's Republic of China). Blue points means in control normal variability. Green points means trending within control.

Abbreviations: EPO, recombinant human erythropoietin; USL, upper specification limit; LSL, lower specification limit; ucl, upper control limit; Icl, lower control limit; cl, center line (mean).

interval 65-144). Different potencies were demonstrated, even between samples from the same manufacturer. Still, in vivo assays remain the most relevant method for comparing biological activity between products. Biological assay of the EPO vials provided by each bulk supplier was performed by an independent laboratory, and the results were confirmed to that of each supplier (Figure 11).

\section{Potency of epoetin in the EPO vial}

The potency of EPO was tested using the ELISA technique with two different types of EPO kit and filling machine. As shown in Figure 12, good results were obtained when the buffer was changed from phosphate to citrate. The type of filling machine also played a critical role in this improvement. A comparative study was done to compare the results obtained for the ELISA immunoassays from both the bulk suppliers of EPO and the results are shown in Figure 12. It is most likely that the Excel Biology/Gentime (Shibayagi Co. Ltd., Shibukawa, Japan) ELISA kit was better than the R\&D Systems
(Minneapolis, MN, USA) ELISA kit because of its more precise results. It can be concluded that the filling machine is a critical factor to be taken into account when predicting the potency of the EPO vials produced. Further, personnel in the production department had the education, background, training, and experience necessary to ensure that all manufacturing procedures were correctly implemented during our study.

It was a possibility that the vials were formulating above the target potency tested at SEDICO by about $11.5 \%$, and also above the biological assay tested for supplier A by about $10.5 \%$. Statistically, there is a $5.3 \%$ probability to get out of specification results (above the upper specification limit of the potency) because the upper control limit reaches 144.6\% in the biological assay, and $131.6 \%$ in the ELISA, as shown in Figures 11 and 12, respectively.

Therefore, corrective action was taken by controlling the fill volume and/or dilution using an in process method for controlling the EPO concentration. The fill volume of the EPO vials being produced was monitored, and an initial increase in

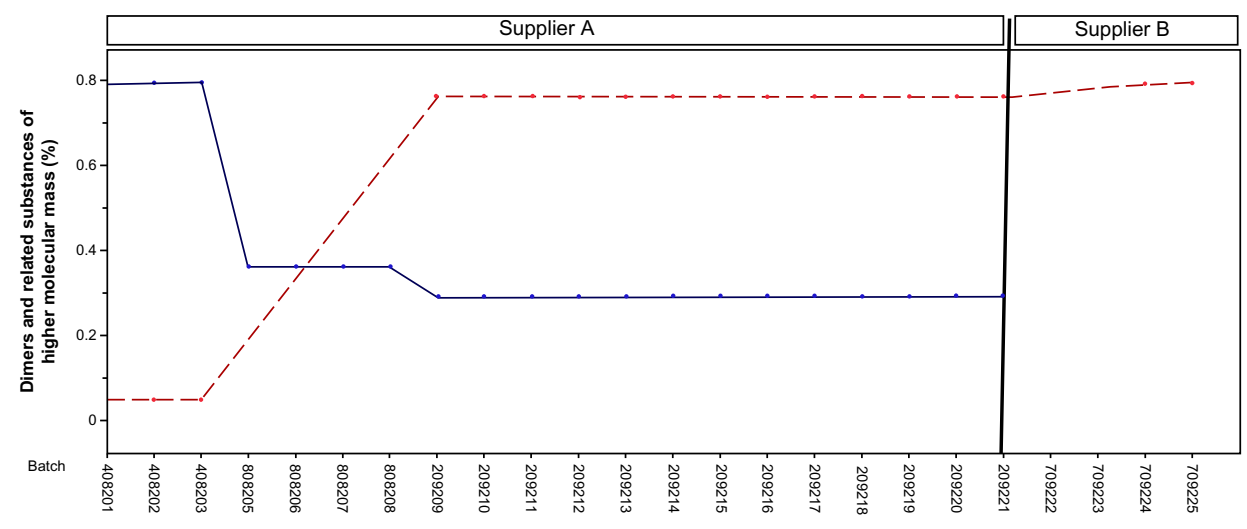

Figure 5 Dimers and related substances of higher molecular mass (NMT 2\%).

Notes: Supplier A is Zelltek S.A. (Santa Fe, Argentina). Supplier B is Sciprogen Bio-pharmaceutical Co., Ltd (People's Republic of China).

Abbreviations: NMT, not more than; SEDICO, South Egypt Drug Industries Company. 


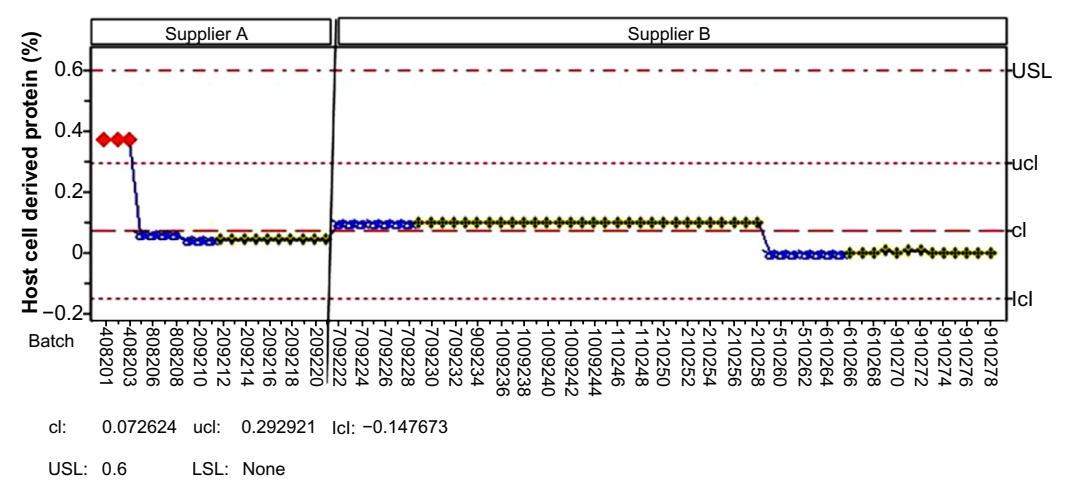

Figure 6 Host cell derived proteins in concentrated EPO solution (NMT 0.6\%).

Notes: Supplier A is Zelltek S.A. (Santa Fe, Argentina). Supplier B is Sciprogen Bio-pharmaceutical Co., Ltd (People's Republic of China). Blue points means in control normal variability. Green points means trending within control. Red points means out of control limit.

Abbreviations: EPO, recombinant human erythropoietin; NMT, not more than; USL, upper specification limit; LSL, lower specification limit; ucl, upper control limit; Icl, lower control limit; cl, center line (mean).

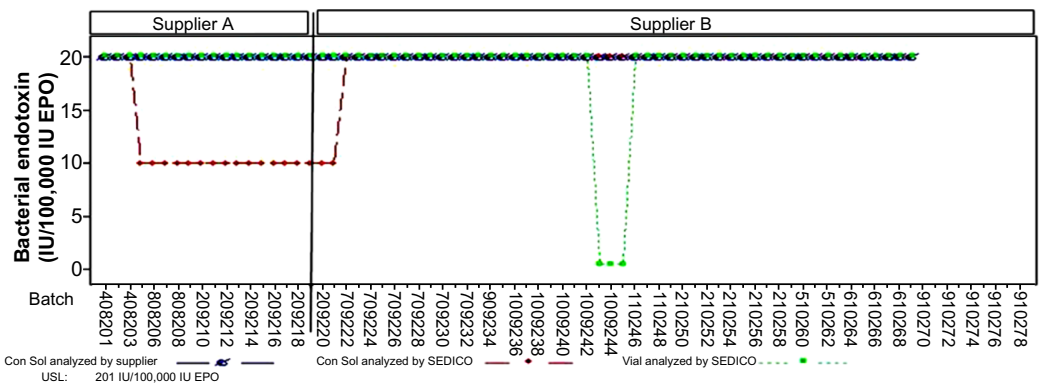

Figure 7 Bacterial endotoxin of concentrated solution and finished product (NMT 20 IU/I 00,000 IU EPO).

Notes: Supplier A is Zelltek S.A. (Santa Fe, Argentina). Supplier B is Sciprogen Bio-pharmaceutical Co., Ltd (People's Republic of China).

Abbreviations: EPO, recombinant human erythropoietin; NMT, not more than; USL, upper specification limit; Con, concentrated; Sol, solution; SEDICO, South Egypt Drug Industries Company.

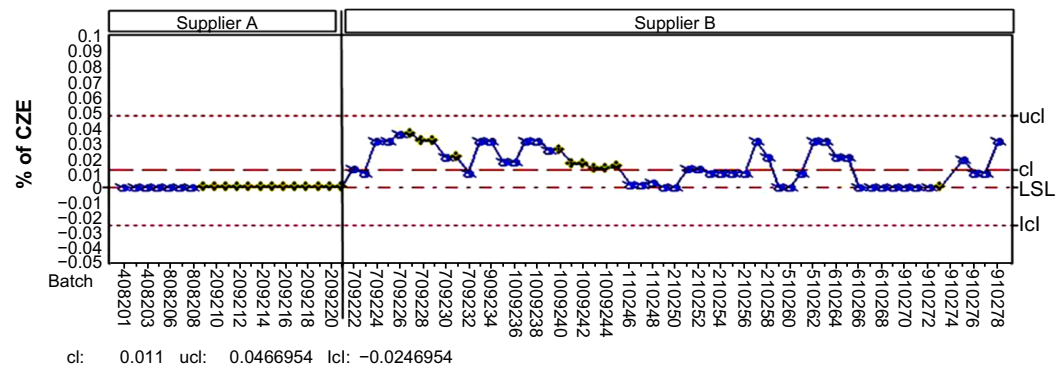

0.011 ucl: 0.0466954 Icl: -0.0246954

USL: 15 LSL: 0

Figure $8 \mathrm{CZE}$ results for isoform I in concentrated solution (0\%-I5\%).

Notes: Supplier A is Zelltek S.A. (Santa Fe, Argentina). Supplier B is Sciprogen Bio-pharmaceutical Co., Ltd (People's Republic of China). Blue points means in control normal variability. Green points means trending within control.

Abbreviations: USL, upper specification limit; LSL, lower specification limit; ucl, upper control limit; Icl, lower control limit; cl, center line (mean); CZE, capillary zone electrophoresis.

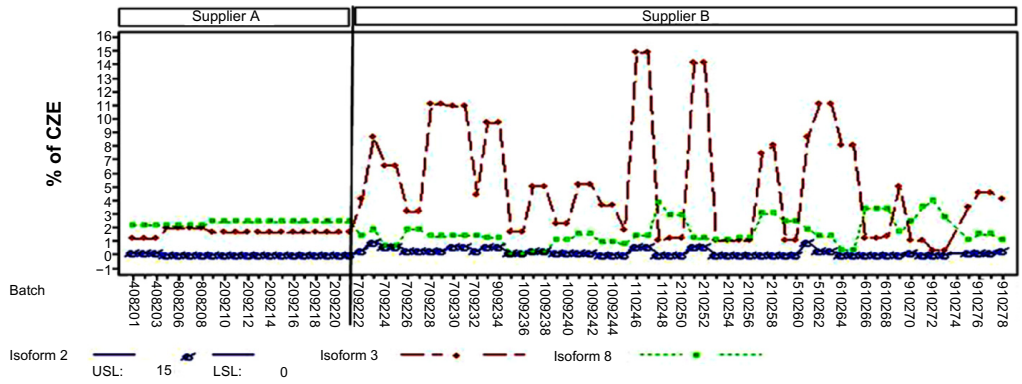

Figure 9 CZE results for isoforms 2, 3 and 8 in concentrated solution (isoforms 2 and $8(0 \%-15 \%)$ and isoform $3(1 \%-20 \%)$ ).

Notes: Supplier A is Zelltek S.A. (Santa Fe, Argentina). Supplier B is Sciprogen Bio-pharmaceutical Co., Ltd (People's Republic of China).

Abbreviations: USL, upper specification limit; LSL, lower specification limit; CZE, capillary zone electrophoresis. 


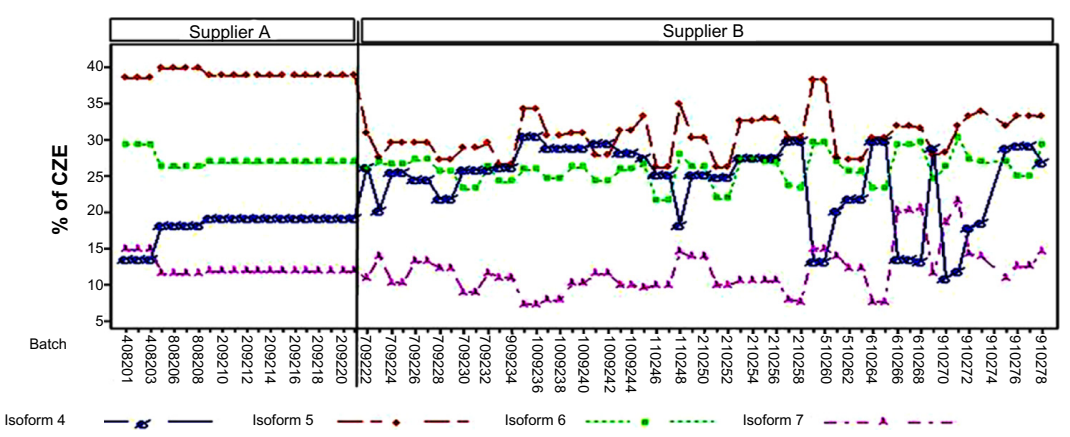

Figure 10 CZE results for isoforms 4, 5, 6 and 7 in concentrated solution CZE (isoforms 4 and 6 (10\%-35\%), isoform 5 (I5\%-40\%) and isoform 7 (5\%-25\%)). Notes: Supplier A is Zelltek S.A. (Santa Fe, Argentina). Supplier B is Sciprogen Bio-pharmaceutical Co., Ltd (People's Republic of China).

Abbreviation: CZE, capillary zone electrophoresis.

fill volume above the optimum level was observed (Figure 13), which was followed by a sharp decrease. Therefore, a request was made to switch to the Bosch filling and capping machine to obtain a more precise fill volume. It was important to do this to minimize the risk of being out of specification and to obtain a better yield by keeping the filling volume as low as possible but still within the accepted volume range. In process controls were highly recommended during process revalidation to evaluate the data and adjust the process in order to achieve the best yield. This proposed capillary electrophoresis method included discontinuous buffer with aqueous nickel to separate both proteins; the erythropoietin and albumin.

\section{Total protein content in the finished vial product}

The effects of different buffers (phosphate and citrate) on total protein content in the EPO vials were determined by SEDICO (Figure 14). More recent batches produced more precise results than the middle batches regardless of bulk supplier and/or buffer used. This difference might be attributable to use of a new filling machine (model MLF3002, year 2009) instead of the older machine (model VLM8010, year 1989)
(Bosch Lab Systems, Waiblingen, Germany). The specific activity and percent protein content in the bulk concentrated solution were also tested by the suppliers, and their results were within the acceptable range (Figures 1 and 4).

\section{Trend control of $\mathrm{pH}$}

The $\mathrm{pH}$ of the finished product in the EPO 4,000 IU vials was determined according to supplier and formulation buffer used. The $\mathrm{pH}$ was approaching the upper limit. Effective preventative measures were established in order to control this. The $\mathrm{pH}$ of different strengths of the EPO product $(4,000$ IU and 2,000 IU) was recommended to be studied over the whole production line in the plant. Also, an alert and action limits were developed. After the gradual increase in the $\mathrm{pH}$ a trend control was taken to achieve the optimum $\mathrm{pH}$ (Figure 15). The citrate buffer and the modification in the addition method of buffer gave a positive effect in $\mathrm{pH}$ adjustment.

\section{Stability}

Both real-time and accelerated studies were performed to obtain stability data. The $\mathrm{pH}$, total protein content, and potency were investigated, and all were found to be acceptable.

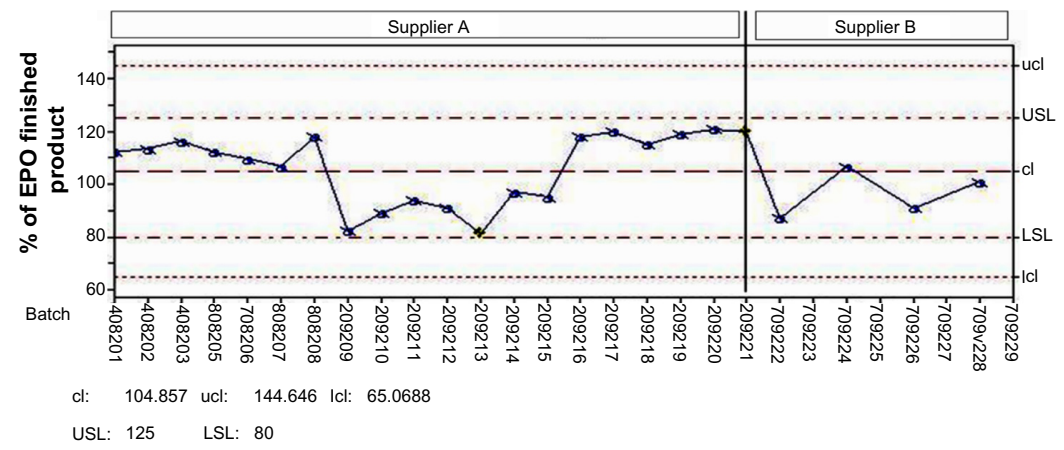

Figure I I Biological assay of EPO finished product (80\%-I25\%).

Notes: Supplier A is Zelltek S.A. (Santa Fe,Argentina). Supplier B is Sciprogen Bio-pharmaceutical Co., Ltd (People's Republic of China). Blue points means in control normal variability.

Abbreviations: USL, upper specification limit; LSL, lower specification limit; ucl, upper control limit; Icl, lower control limit; cl, center line (mean); EPO, recombinant human erythropoietin. 


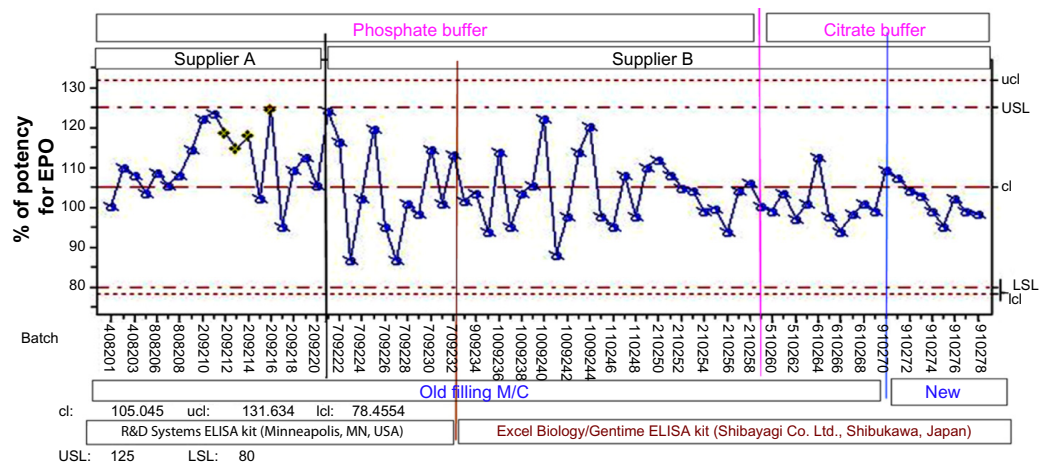

Figure 12 ELISA results for immunoassay of EPO finished product $(3,200-5,000 \mathrm{IU} / \mathrm{mL})$.

Notes: Supplier A is Zelltek S.A. (Santa Fe,Argentina). Supplier B is Sciprogen Bio-pharmaceutical Co., Ltd (People's Republic of China). Blue points means in control normal variability. Green points means trending within control. New (model MLF3002, year 2009) and older (model VLM80I0, year I989) filling machines were used (Bosch Lab Systems, Waiblingen, Germany). The vertical brown line separates between R\&D Systems ELISA kit and Excel Biology/Gentime ELISA kit. The vertical pink line separates between phosphate buffer and citrate buffer.The vertical blue line separates between old filling machine and new filling machine.

Abbreviations: USL, upper specification limit; LSL, lower specification limit; ucl, upper control limit; Icl, lower control limit; cl, center line (mean); ELISA, enzyme-linked immunosorbent assay; EPO, recombinant human erythropoietin; M/C, machine.

Stability study of the first three batches (408201-408203) concluded that the results are acceptable but that the potency was affected by the accelerated conditions. At the end of 2 years, (recommended shelf life), for the real-time stability study, no points were outside the specification limits. This stability profile encouraged us to extend the stability studies over period longer than 24 months for future to further examine the extended pattern of the product stability profile. Extension of shelf life will be studied in the future (Figures 16-21).

\section{Clinical safety and efficacy}

SEDICO epoetin was given intravenously at an initial dose of 150 $\mathrm{IU} / \mathrm{kg}$ body weight per week in two equal doses after dialysis and titrated according to percent hematocrit response as per K-DOQI (National Kidney Foundation Kidney Disease Outcomes Quality Initiative) guidelines. All relevant factors, including iron status, were also monitored and managed according to K-DOQI guidelines. The mean interval between diagnosis of end-stage kidney disease and enrollment in the study was 60 (range 30-90) days. Hemoglobin increased, with the increase being significant as early as 4 weeks, reaching a mean of $9.45 \pm 1.7 \mathrm{~g} / \mathrm{dL}$ at week 12 from a mean baseline value of $8.34 \mathrm{~g} / \mathrm{dL}$. There was also a significant increase in hematocrit (from $26.74 \%$ to $32.22 \%$ ). The success rate over the 12-week study period was deemed to be $95 \%$ in view of an absolute increase in hemoglobin of 1,883 g/ $\mathrm{dL}$ (hematocrit 5.48\%) as a target per K-DOQI guidelines. No significant difference in response was seen between females and males at any stage during the study. Blood pressure remained stable throughout the study in the 12 patients with a documented history of hypertension at study entry. There was no increase in frequency of thrombotic episodes or requirement for heparin during dialysis sessions. No dropouts due to lack of tolerability were reported at any study center. Overall, the side effect profile was similar to that of other erythropoietins.

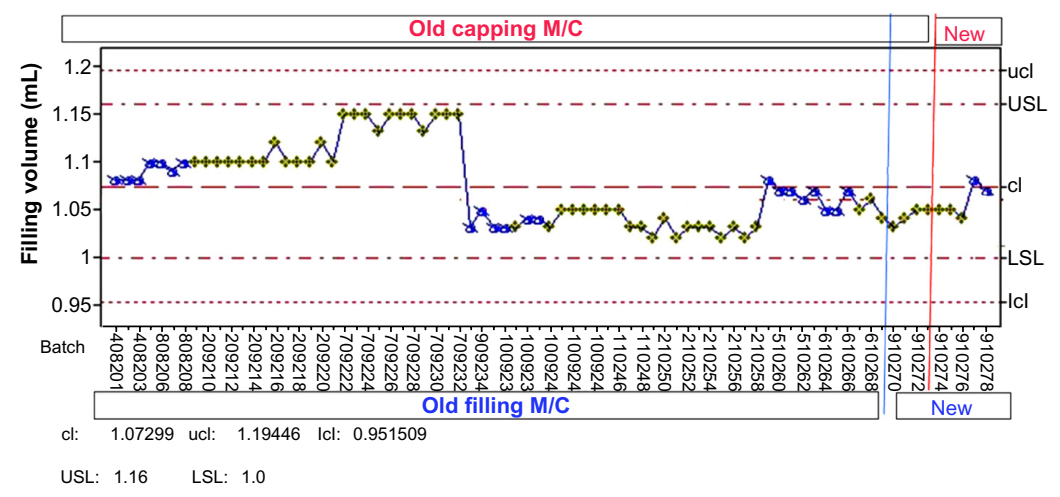

Figure I 3 Filling volume of EPO finished product (I.00-I.16 mL).

Notes: Supplier A is Zelltek S.A. (Santa Fe,Argentina). Supplier B is Sciprogen Bio-pharmaceutical Co., Ltd (People's Republic of China). Blue points means in control normal variability. Green points means trending within control. New (model MLF3002, year 2009) and older (model VLM80I0, year 1989) filling machines were used (Bosch Lab Systems, Waiblingen, Germany). The vertical blue line separates between old filling machine and new filling machine. The vertical red line separates between old capping machine and new capping machine.

Abbreviations: USL, upper specification limit; LSL, lower specification limit; ucl, upper control limit; Icl, lower control limit; cl, center line (mean); EPO, recombinant human erythropoietin; M/C, machine. 


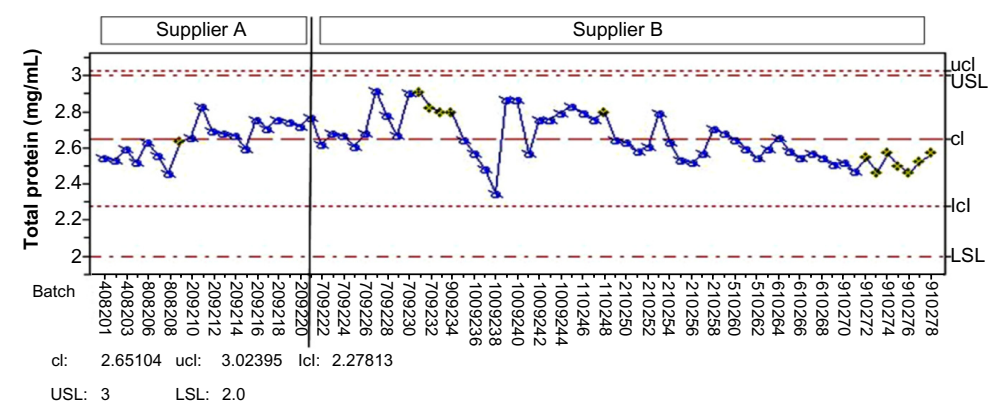

Figure 14 Total protein of EPO finished product $(2-3 \mathrm{mg} / \mathrm{mL})$

Notes: Supplier A is Zelltek S.A. (Santa Fe, Argentina). Supplier B is Sciprogen Bio-pharmaceutical Co., Ltd (People's Republic of China). Blue points means in control normal variability. Green points means trending within control.

Abbreviations: USL, upper specification limit; LSL, lower specification limit; ucl, upper control limit; Icl, lower control limit; cl, center line (mean); EPO, recombinant human erythropoietin.

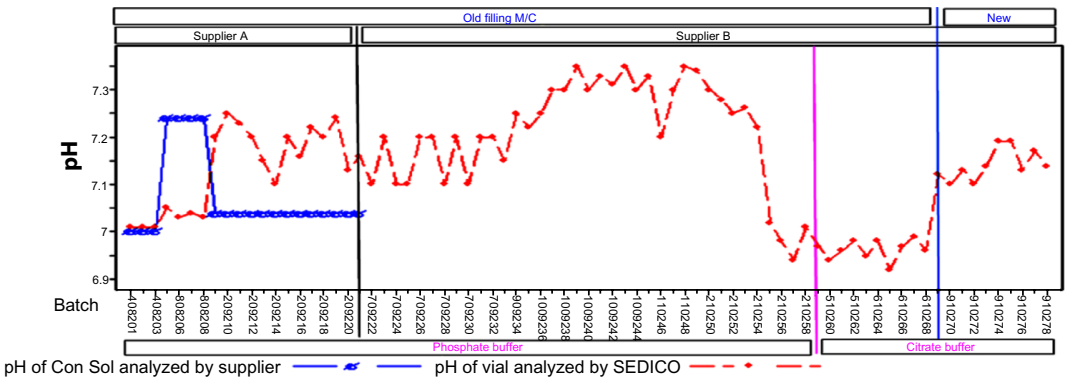

Figure $15 \mathrm{pH}$ monitoring of different batches (6.5-7.5).

Notes: Supplier A is Zelltek S.A. (Santa Fe, Argentina). Supplier B is Sciprogen Bio-pharmaceutical Co., Ltd (People's Republic of China). New (model MLF3002, year 2009) and older (model VLM80I0, year 1989) filling machines were used (Bosch Lab Systems, Waiblingen, Germany). The vertical pink line separates between phosphate buffer and citrate buffer. The vertical blue line separates between old filling machine and new filling machine.

Abbreviations: Con, concentration; Sol, solution; M/C, machine; SEDICO, South Egypt Drug Industries Company.

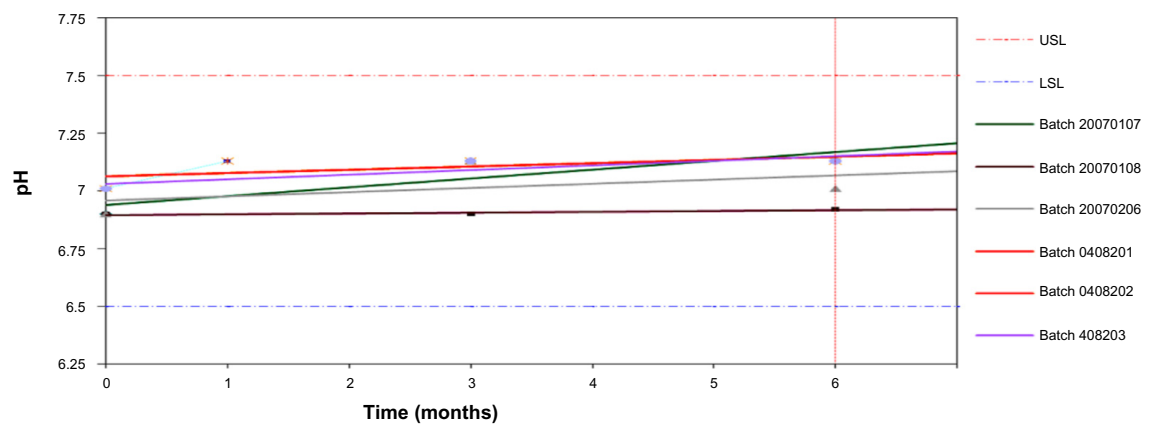

Figure 16 Accelerated stability study $\left(25^{\circ} \mathrm{C} \pm 3^{\circ} \mathrm{C}\right)$ of epoetin $4,000 \mathrm{IU}$ vial $-\mathrm{pH}$.

Note: Red vertical line indicates the end of the study.

Abbreviations: USL, upper specification limit; LSL, lower specification limit.

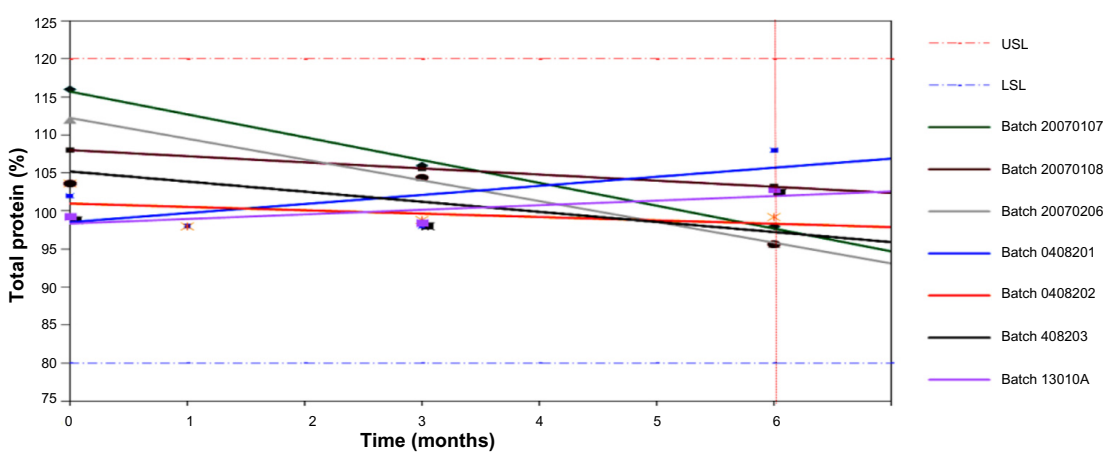

Figure 17 Accelerated stability study $\left(25^{\circ} \mathrm{C} \pm 3^{\circ} \mathrm{C}\right)$ of EPO 4,000 IU vial - total protein.

Note: Red vertical line indicates the end of the study.

Abbreviations: USL, upper specification limit; LSL, lower specification limit; EPO, recombinant human erythropoietin. 


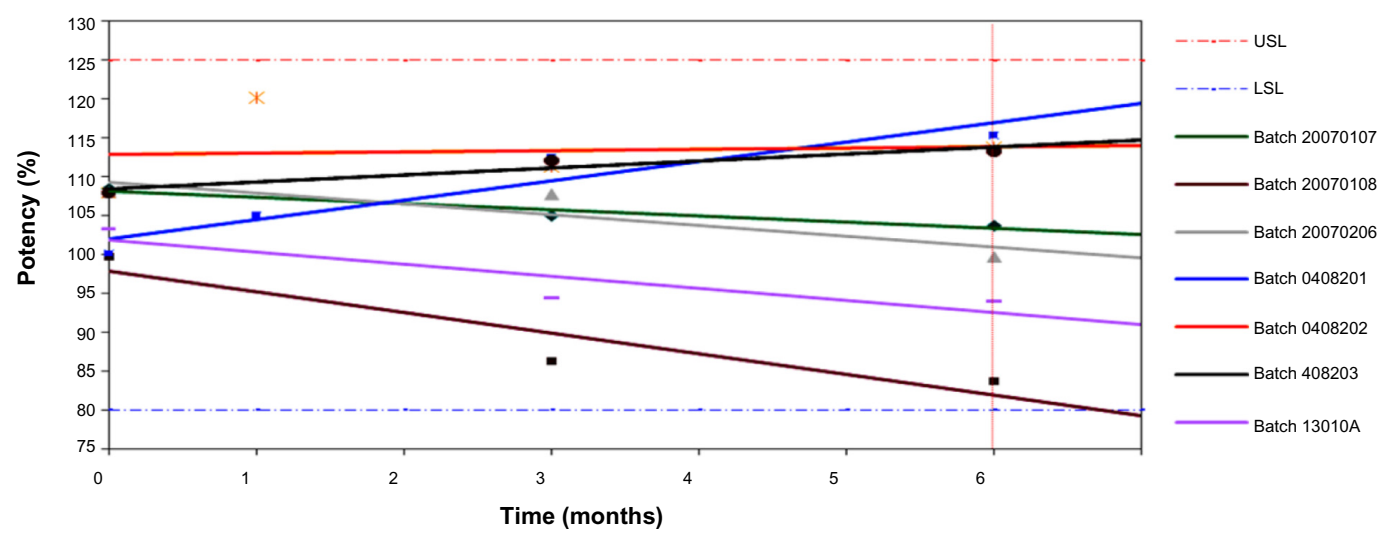

Figure 18 Accelerated stability study $\left(25^{\circ} \mathrm{C} \pm 3^{\circ} \mathrm{C}\right)$ of EPO 4,000 IU vial - potency.

Note: Red vertical line indicates the end of the study.

Abbreviations: USL, upper specification limit; LSL, lower specification limit; EPO, recombinant human erythropoietin.

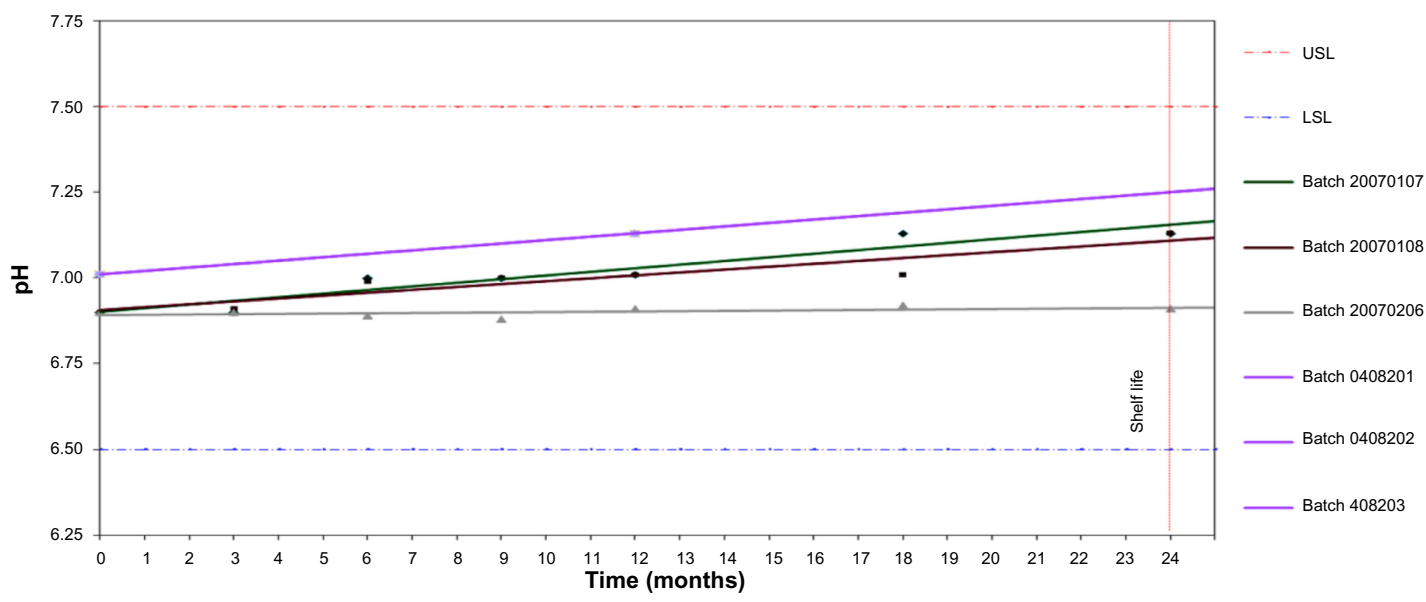

Figure 19 Real-time stability study $\left(5^{\circ} \mathrm{C} \pm 3^{\circ} \mathrm{C}\right)$ of EPO $4,000 \mathrm{IU}$ vial $-\mathrm{pH}$

Note: Red vertical line indicates the end of the study.

Abbreviations: USL, upper specification limit; LSL, lower specification limit; EPO, recombinant human erythropoietin.

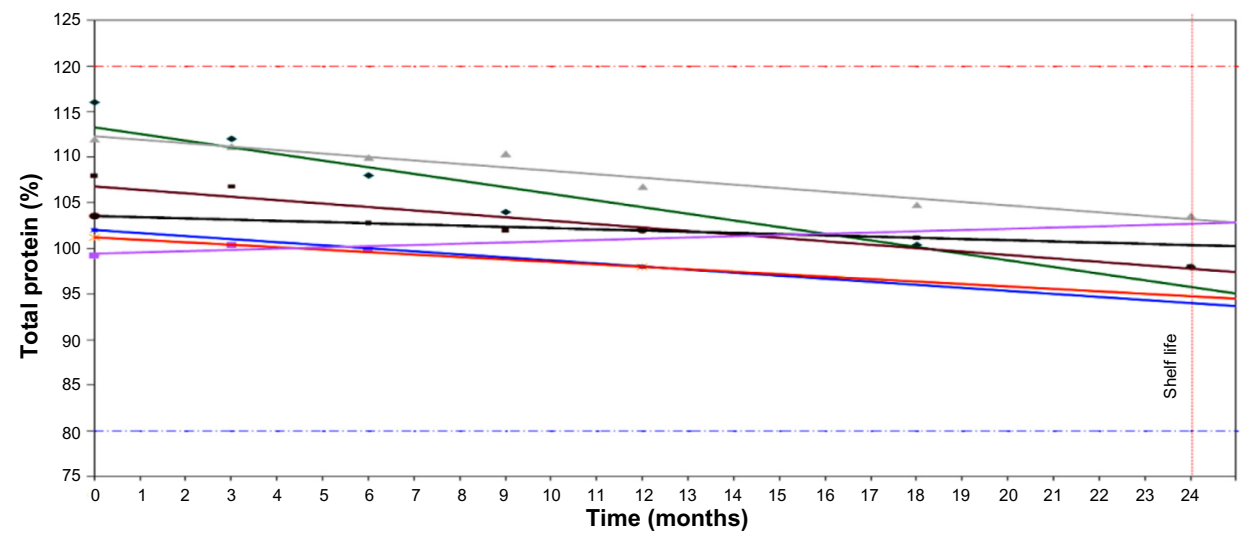

—_Batch 20070107

- Batch 20070108

_ Batch 2007020

Batch 0408201

—Batch 0408202

_Batch 408203

Batch 13010A

Figure 20 Real-time stability study $\left(5^{\circ} \mathrm{C} \pm 3^{\circ} \mathrm{C}\right)$ of epoetin $4,000 \mathrm{IU}$ vial - total protein.

Note: Red vertical line indicates the end of the study.

Abbreviations: USL, upper specification limit; LSL, lower specification limit. 


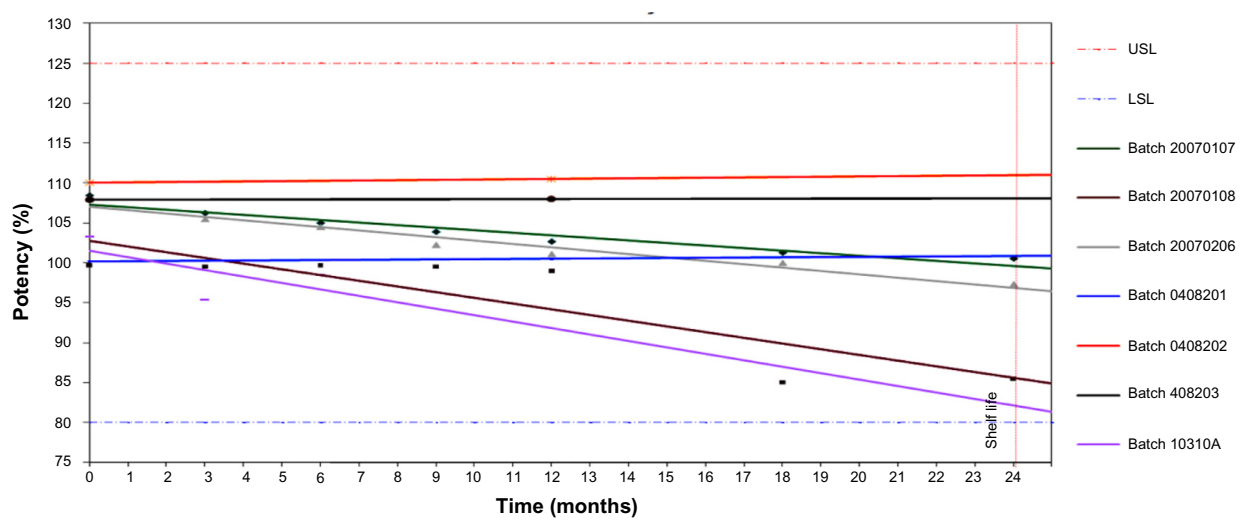

Figure 2 I Real-time stability study $\left(5^{\circ} \mathrm{C} \pm 3^{\circ} \mathrm{C}\right)$ of epoetin $4,000 \mathrm{IU}$ vial - potency.

Note: Red vertical line indicates the end of the study.

Abbreviations: USL, upper specification limit; LSL, lower specification limit.

\section{Other tests}

To confirm the quality and reliability of our results, the test data for the suppliers and SEDICO were compared on the same chart. One of these comparisons included an assay for bacterial endotoxins in the concentrated solution contained in the finished vial provided by the suppliers and SEDICO. All values were within range. Identification of concentrated erythropoietin solutions was achieved by four methods, ie, polyacrylamide gel electrophoresis, immunoblotting, peptide mapping, and capillary electrophoresis. The results of these four tests were confirmed for all batches. Other parameters, including sealing and vial clarity were within acceptable limits for the finished vials.

\section{Conclusion}

Lower cost is the main reason for using biosimilar products in developing countries. SEDICO supplies EPO of acceptable quality at an affordable price. The quality of the EPO supplied by SEDICO was determined by analytical methods, and we are now able to provide EPO with cost-savings over Eprex $^{\circledR}$. According to Information Management System data, the SEDICO EPO biosimilar accounted for $51.3 \%$ of the total units sold from 2009 to 2012, and produced savings to the Egyptian market of approximately $\$ 3.8$ million during these four years of marketing. However, the issues are not as simple as cost alone, because the quality of the biosimilar needs to be shown to be equivalent to that of the original. This paper discusses the analytical tests used to demonstrate the comparability and similarity of EPO as a biosimilar product and a reference drug with respect to protein content, activity, physiochemical integrity and stability, and immunogenicity. Although several assays are available, reliable tests for safety and efficacy require further development. Standardization and validation of assays and presentation of data are crucial for future credible testing of biosimilars. However, only clinical studies and post-authorization pharmacovigilance can provide the necessary evidence regarding product quality. In this work, the EPO product was investigated in a multicenter study involving seven universities and five medical centers in Egypt. The principles of continuous monitoring, quality by design, good handling, and management of changes should be applied. Regular updating of references and continuous awareness of process knowledge will assist in improving product quality.

\section{Acknowledgment}

Thanks are due to Professor Hossam Aboul Enein of SEDICO for his continuous help and support.

\section{Disclosure}

The authors report no conflicts of interest in this work.

\section{References}

1. Reichert JM. Trends in US approvals: new biopharmaceuticals and vaccines. Trends Biotechnol. 2006;24(7):293-298.

2. Roger SD. Biosimilars: how similar or dissimilar are they? Nephrology. 2006;11(4):341-346.

3. Johnson PE. Implications of biosimilars for the future. Am J Health Syst Pharm. 2008;65(14):S16-S22.

4. Frank RG. Regulation of follow-on biologics. $N$ Engl $J$ Med. 2007;357(9):841-843.

5. Schellekens H. Follow-on biologics: challenges of the 'next generation'. Nephrol Dial Transplant. 2005;20(4):31-36.

6. Chirino AJ, Mire-Sluis A. Characterizing biological products and assessing comparability following manufacturing changes. Nat Biotechnol. 2004;22(11):1383-1391. 
7. Chirino AJ, Ary ML, Marshall SA. Minimizing the immunogenicity of protein therapeutics. Drug Discov Today. 2004;9(2):82-90.

8. Mellstedt H, Niederwieser D, Ludwig $\mathrm{H}$. The challenge of biosimilars. Ann Oncol. 2008;19(3):411-419.

9. Eldawy MA. Globalization and access to biotechnology-derived health care products: a view from Egypt. In: Ismail Serageldin, Persley GJ, editors. Biotechnology and Sustainable Development: Voices of the South and North. Cambridge, MA, USA: CABI; 2003.

10. Abdelgafar B, Thorsteinsdottir H, Quach U, Singer PA, Daar AS. The emergence of Egyptian biotechnology from generics. Nat Biotechnol. 2004;22 Suppl:DC25-DC30.

11. Aapro M, Cornes P, Sun D, Abraham I. Comparative cost efficiency across the European G5 countries of originators and a biosimilar erythropoiesis-stimulating agent to manage chemotherapy-induced anemia in patients with cancer. Ther Adv Med Oncol. 2012;4(3):95-105.

12. European Medicines Agency. Committee for Medicinal Products for Human Use. Annex to guideline on similar biological medicinal products containing biotechnology-derived proteins as active substance: non-clinical and clinical issues. Guidance on similar medicinal products containing recombinant erythropoietins. Available from: http//:www.tga. gov.au/DOCS/pdf/euguide/bmwp/9452605en.pdf. Accessed March 26, 2006.

13. Lisowska $\mathrm{E}$. The role of glycosylation in protein antigenic properties. Cell Mol Life Sci. 2002;59(3):445-455.

14. Singh AK, Szczech L, Tang KL, et al. Correction of anemia with epoetin alfa in chronic kidney disease. $N$ Engl J Med. 2006;355(20): 2085-2098.
15. Bohlius J, Wilson J, Seidenfeld J, et al. Recombinant human erythropoietins and cancer patients: updated meta-analysis of 57 studies including 9353 patients. J Natl Cancer Inst. 2006;98(10):708-714.

16. Dicato M, Plawny L. Erythropoietin in cancer patients: pros and cons. Curr Opin Oncol. 2010;22(4):307-311.

17. Glaspy JA. Erythropoietin in cancer patients. Annu Rev Med. 2009;60: 181-192.

18. European Pharmacopoeia. Erythropoietin Concentrated Solution, Monograph 1316. 7th ed. Strasbourg, France: Council of Europe; 2010(vol 2). 2010.

19. Hoesel W, Gross J, Moller R, et al. Development and evaluation of a new ELISA for the detection and quantification of antierythropoietin antibodies in human sera. J Immunol Methods. 2004;294(1-2): 101-110.

20. Locatelli F, Roger S. Comparative testing and pharmacovigilance of biosimilars. Nephrol Dial Transplant. 2006;21 Suppl 5:13-16.

21. Schellekens H. Biosimilar epoetins: how similar are they. Eur J Hosp Pharm. 2004;3:43-47.

22. Egrie JC, Browne JK. Development and characterization of novel erythropoiesis stimulating protein (NESP). Nephrol Dial Transplant. 2001;16 Suppl 3:3-13.

23. Byrne B, Donohoe GG, O'Kennedy R. Sialic acids: carbohydrate moieties that influence the biological and physical properties of biopharmaceutical proteins and living cells. Drug Discov Today. 2007;12(7):319-326.
Biosimilars

\section{Publish your work in this journal}

Biosimilars is an international, peer-reviewed, open access journal focusing on the manufacture, development and medicinal use of biopharmaceutical compounds considered similar to an innovator agent. Specific topics covered in the journal include: Regulatory issues and pathways; manufacturing processes; chemical composition and

\section{Dovepress}

structure; quality and purity; patent issues; bioequivalence and interchangeability; clinical efficacy data; patient perspectives. The manuscript management system is completely online and includes a very quick and fair peer-review system. Visit http://www.dovepress.com/ testimonials.php to read real quotes from published authors. 